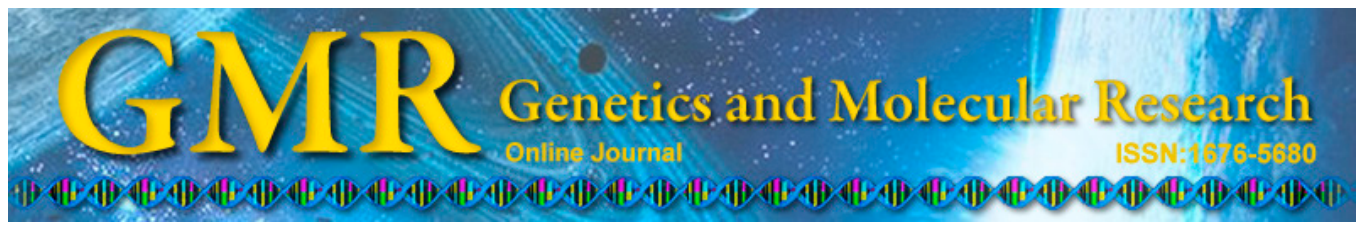

\title{
Correlation of $\mathrm{CD}_{4}^{+} \mathrm{CD}_{25}{ }^{+} \mathrm{Foxp}_{3}{ }^{+}$Treg with the recovery of joint function after total knee replacement in rats with osteoarthritis
}

\author{
S.-Y. Guo*, Y.-J. Ding*, L. Li, T. Zhang, Z.-Z. Zhang and E.-S. Zhang \\ Department of Orthopaedics, Jinan Central Hospital Affiliated to Shandong \\ University, Jinan, Shandong, China \\ *These authors contributed equally to this study. \\ Corresponding author: S.-Y. Guo \\ E-mail: ShuyaGuo2014@163.com
}

Genet. Mol. Res. 14 (3): 7290-7296 (2015)

Received June 27, 2014

Accepted September 11, 2014

Published July 3, 2015

DOI http://dx.doi.org/10.4238/2015.July.3.4

\begin{abstract}
In this study, we observed changes in $\mathrm{CD}_{4}^{+} \mathrm{CD}_{25}^{+}$ $\mathrm{Foxp}_{3}{ }^{+}$Treg expression in rats with osteoarthritis (OA) to explore the role that $\mathrm{CD}_{4}^{+} \mathrm{CD}_{25}{ }^{+} \mathrm{Foxp}_{3}{ }^{+}$Treg plays in the decline in the condition of OA rats. Thirty rats were randomly divided into 2 groups equally and OA was induced in rats in the model group by injection of papain and L-cysteine into the right knee joint. Cartilage lesions were scored by the modified Mankin scale; pulmonary function was assessed by spirometry; interleukin (IL)-17 and IL-4 levels were evaluated by the enzyme-linked immunosorbent assay; and the levels of $\mathrm{CD}_{4}^{+} \mathrm{CD}_{25}{ }^{+}$ Foxp $_{3}{ }^{+}$Treg in peripheral blood were measured by flow cytometry. The left knee joints of the model rats appeared palpable swelling and osteophytes, while the body weight, heart and lung function of these rats decreased. The serum IL-4 level was lower, whereas the serum IL-17 level was higher in the model group $(\mathrm{P}<0.05)$. The peripheral blood $\mathrm{CD}_{4}^{+} \mathrm{CD}_{25}{ }^{+} \mathrm{Foxp}_{3}{ }^{+}$Treg of $\mathrm{CD}^{+} \mathrm{T}$ cells was significantly
\end{abstract}




$$
\mathrm{CD}_{4}^{+} \mathrm{CD}_{25}{ }^{+} \text {Foxp }{ }_{3}^{+} \text {Treg in osteoarthritis }
$$

lower. Correlation of the changes in the levels of IL-4, IL-17, and Treg suggests that the underlying mechanism may be a reduction of the regulatory effect of Treg. The specific mechanism still requires further study.

Key words: Cardiopulmonary function; Regulatory T cells; Interleukin; Osteoarthritis

\section{INTRODUCTION}

Osteoarthritis (OA) is a type of rheumatic disease. Clinical studies have shown that OA patients not only have symptoms of arthritis but also may have chest tightness, palpitations, and other systemic symptoms. With increased severity of OA, systemic symptoms also become more severe. $\mathrm{CD}_{4}^{+} \mathrm{CD}_{25}{ }^{+} \mathrm{Foxp}_{3}{ }^{+}$and regulatory cells are essential for controlling in vivo autoimmune reactivity. In addition to maintaining the body's normal immune response, they are involved in the negative regulation of the immune response. If an immune reaction is too strong, it can trigger autoimmune disease. Interleukin (IL)-4 and IL-17 are important cytokines that play a regulatory role in the inflammatory response (Zhang et al., 2011). We used a rat model of OA to observe the effects of OA on cardiac and pulmonary function, expression of cytokines IL-4 and IL-17 in the peripheral blood, and changes in $\mathrm{CD}_{4}^{+} \mathrm{CD}_{25}{ }^{+} \mathrm{Foxp}_{3}{ }^{+}$Treg levels. A correlation analysis was then performed to assess the effect of $\mathrm{OA}$ on rat cardiac and pulmonary function and its underlying mechanism (Wang et al., 2012).

\section{MATERIAL AND METHODS}

\section{The experimental animals}

Thirty clean-grade male Wistar rats, aged 20-30 weeks, of average quality (180 \pm $30.5 \mathrm{~kg}$ ), were provided by the Experimental Animal Centre of Shandong University. They were randomly divided into a model group and control group, each containing 15 rats. Before beginning the experiment, the animals were raised according to the cleanest grade standard for conventional breeding, fed for 1 week before the experiment, and exposed to a 12-h light/dark cycle. They were also examined to confirm the absence of any abnormalities before the experiment started. All animals were raised in strict accordance with the Animal Ethical Standard, and this study was approved by the Experimental Animal Centre of Shandong University, Shandong Province Ethics Committee.

\section{Experimental materials}

L-cysteine and papain were purchased from Merck, USA. The IL-4, IL-17 ELISA Kit (batch No. 1202156202963), $\mathrm{CD}_{4}$ fluorescein isothiocyanate-labeled single antibody (batch No. 11-0040-81), $\mathrm{CD}_{25}$ phycoerythrin-cyanine dye-labeled single antibody (batch No. 11-0040-45), and Foxp 3 single antibody of algae red protein marker (batch No. 110040-76), were obtained from eBioscience Inc., USA. 


\section{Experimental equipment}

The equipment used included the following: ultrasonic diagnostic apparatus (GE Vivid 7, USA), animal respirator, pulmonary function analysis system (AniRes2003, Bei Lanbo, Beijing), high speed centrifugal chiller (Centrifuge 5417R, Eppendorf, Germany), flow cytometry (Epics XL, Beckman Coulter, USA), and Guang Xuexian mirror (Olympus, Japan).

\section{The experimental method}

\section{Rat arthritis model preparation}

The rat model of OA was created by injecting $25 \mu \mathrm{L}$ of a mixture of $0.02 \mathrm{M} \mathrm{L}$-cysteine and $4 \%$ papain into the left knee joint during the feeding period, then at 3 and 5 days later.

\section{Pathological observation}

On day 50 after the injection, the animals were sacrificed, and their knees were opened. Observation was made with both the naked eye and the light microscope, and the intra-articular synovium and articular cartilage were scored using the modified Mankin scale.

\section{Measurement of cardiac function}

On day 50 of the rat model, 2 groups of 10 rats were randomly selected, and anesthetized for evaluation of heart function. Two-dimensional images of the left ventricular (LV) long axis parasternal wall were obtained, and the following parameters were measured: stroke volume (SV), interventricular septal (IVS) thickness, LV diameter, posterior wall (LVPW) thickness, early (E) and late (A) LV diastolic peak velocity, E/A ratio, LV end-systolic and end-diastolic diameters, LV short-axis fractional shortening (FS\%), and ejection fraction (EF). Continuous measurement of these parameters was performed at least 3 times, and the mean values were calculated.

\section{Pulmonary function tests}

On day 50 of the rat model, spirometry was performed to determine the pulmonary function of the rats. Forced vital capacity (FVC), maximal expiratory flow volume of 25,50 , and $75 \%$ of vital capacity (FEF25, FEF50, FEF75), forced expiratory volume in $1 \mathrm{~s}$ (FEV1), maximal expiratory flow (PEF), maximal midexpiratory flow (MMF), and other indicators were measured.

\section{Enzyme-linked immunosorbent assay (ELISA) and flow cytometry assay}

ELISA and flow cytometry assays were performed to determine the levels of IL-4, IL-17, and $\mathrm{CD}_{4}^{+} \mathrm{CD}_{25}{ }^{+} \mathrm{Foxp}_{3}^{+}$Treg in the peripheral blood of the rats.

\section{Statistical method}

The data were analyzed with SPSS 15.0, using the $t$-test to compare means $\pm \mathrm{s}$ between the 2 groups. Correlation analysis was carried out using Spearman's rank correlation 
coefficient, and $\mathrm{P}<0.05$ was considered to be statistically significant.

\section{RESULTS}

\section{Development of abnormalities}

Eight hours after the first injection, rats in the model group developed left knee joint swelling, local festering, gait instability with the left lower limb not touching down, limp appearance, reduced activity, reduced food intake, and a decrease in body weight. A few of the model rats also developed shortness of breath. After 1-2 weeks, the swelling of the left knee gradually subsided, local ulcers began healing, normal gait was restored, and activity gradually recovered. At around 3 weeks, the left knee joints of the model rats were noted to have palpable swelling and osteophytes. The knees of the control group remained free of abnormalities. On day 50 of the rat model, the body weight of rats in the model group was significantly lower than that of the control group $(\mathrm{P}<0.05$, Table 1$)$.

\begin{tabular}{|c|c|c|c|}
\hline Signs indicators & $\mathrm{N}$ & Model group & Control group \\
\hline \multicolumn{4}{|l|}{ Body mass (g) } \\
\hline Before modeling & 15 & $182.1 \pm 17.9$ & $180.9 \pm 18.2$ \\
\hline 50 days after modeling & 15 & $217.4 \pm 16.3$ & $253.7 \pm 19.6$ \\
\hline \multicolumn{4}{|l|}{ Cardiac function parameters } \\
\hline SV & 10 & $0.44 \pm 0.21$ & $0.18 \pm 0.33$ \\
\hline IVS (mm) & 10 & $2.37 \pm 0.22$ & $2.44 \pm 0.31$ \\
\hline $\mathrm{LV}(\mathrm{mm})$ & 10 & $6.13 \pm 0.74$ & $5.23 \pm 0.65$ \\
\hline LVPW (mm) & 10 & $1.84 \pm 0.23$ & $1.76 \pm 0.18$ \\
\hline E & 10 & $0.51 \pm 0.17$ & $1.56 \pm 0.27$ \\
\hline A & 10 & $1.38 \pm 0.18$ & $0.92 \pm 0.24$ \\
\hline $\mathrm{E} / \mathrm{A}$ & 10 & $0.52 \pm 0.24$ & $1.73 \pm 0.15$ \\
\hline $\mathrm{FS} \%$ & 10 & $45.33 \pm 2.26$ & $55.37 \pm 2.54$ \\
\hline $\mathrm{EF}$ & 10 & $79.74 \pm 4.68$ & $86.28 \pm 4.31$ \\
\hline \multicolumn{4}{|l|}{ Lung function parameters } \\
\hline FVC & 10 & $0.41 \pm 0.25$ & $0.48 \pm 0.76$ \\
\hline $\mathrm{FEF}_{25}(\mathrm{~mL} / \mathrm{s})$ & 10 & $3.63 \pm 0.17$ & $4.21 \pm 0.23$ \\
\hline $\mathrm{FEF}_{50}^{25}(\mathrm{~mL} / \mathrm{s})$ & 10 & $3.21 \pm 0.27$ & $4.65 \pm 0.18$ \\
\hline $\mathrm{FEF}_{75}^{50}(\mathrm{~mL} / \mathrm{s})$ & 10 & $3.11 \pm 0.22$ & $4.87 \pm 0.29$ \\
\hline $\mathrm{FEV}_{1}(\mathrm{~mL} / \mathrm{s})$ & 10 & $0.21 \pm 0.63$ & $0.46 \pm 0.22$ \\
\hline $\mathrm{PEF}(\mathrm{mL} / \mathrm{s})$ & 10 & $2.67 \pm 0.41$ & $4.86 \pm 0.36$ \\
\hline $\mathrm{MMF}(\mathrm{mL} / \mathrm{s})$ & 10 & $3.01 \pm 0.24$ & $4.89 \pm 0.16$ \\
\hline \multicolumn{4}{|l|}{ Interleukin } \\
\hline IL-4 (pg/mL) & 10 & $94.12 \pm 17.33$ & $136.98 \pm 23.74$ \\
\hline IL-7 (pg/L) & 10 & $307.59 \pm 34.62$ & $241.63 \pm 52.11$ \\
\hline $\mathrm{CD}_{4}^{+} \mathrm{CD}_{25}^{+}{ }^{+} \mathrm{Foxp}_{3}{ }^{+}$Treg & 10 & $6.30 \pm 1.25$ & $9.27 \pm 1.01$ \\
\hline
\end{tabular}

$\mathrm{SV}=$ stroke volume; IVS = interventricular septum; LV = left ventricle; $\mathrm{LVPW}=$ left ventricular posterior wall; $\mathrm{E}=$ early left ventricular diastolic peak velocity; A = late left ventricular diastolic peak velocity; FS\% = left ventricular short-axis fractional shortening; $\mathrm{EF}=$ ejection fraction; $\mathrm{FVC}=$ forced vital capacity; $\mathrm{FEF}_{25}=$ maximal expiratory flow at a volume of $25 \%$ of vital capacity; $\mathrm{FEF}_{50}=$ maximal expiratory flow at a volume of $50 \%$ of vital capacity; $\mathrm{FEF}_{75}=$ maximal expiratory flow at a volume of $75 \%$ of vital capacity; $\mathrm{FEV}_{1}=$ forced expiratory volume in $1 \mathrm{~s} ; \mathrm{PEF}$ $=$ peak expiratory flow; MMF = maximal midexpiratory flow; IL-4 = interleukin 4; IL-7 = interleukin 7.

\section{Comparison under light microscopy}

Figure 1 shows the knee joint cartilage of the control group under light microscopy. 
No obvious abnormalities of cartilage cells are seen - the cartilage has a smooth surface and uniform distribution. However, observation of the knee joint cartilage of the model group under light microscopy revealed a rough cartilage surface, some visible fractures, disordered arrangement of cartilage cells, and necrosis. When comparing the 2 groups using the modified Mankin scale, the scores of the model group $(5.17 \pm 0.47)$ were obviously higher than those in the control group $(0.83 \pm 0.56)(\mathrm{P}<0.01$, Table 1$)$.
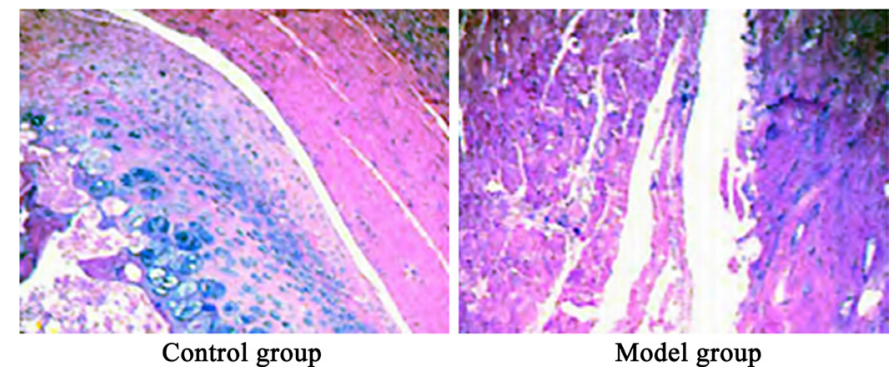

Figure 1. Observation of articular cartilage of two groups (H\&E, 200X).

\section{Heart and lung function comparison}

Table 1 shows that the $\mathrm{E}$ and $\mathrm{E} / \mathrm{A}$ in the model group were significantly lower than those in the control group ( $\mathrm{P}<0.05)$. The differences between SV, A, IVS, LV, LVPW, FS\%, and EF in the 2 groups were not significant $(\mathrm{P}>0.05)$. FEF50, FEF75, FEV1, and PEF were significantly lower in the model group than in the control group $(\mathrm{P}<0.05)$. No significant differences were seen between the 2 groups in FVC and MMF (P $>0.05$, Table 1).

\section{Serum cytokine IL-4 and IL-17 and peripheral blood $\mathrm{CD}_{4}^{+} \mathrm{CD}_{25}{ }^{+} \mathrm{Foxp}_{3}{ }^{+}$Treg levels}

Table 1 shows that in the model group, the serum IL-4 level was lower, whereas the serum IL-17 level was higher than those in the control group $(\mathrm{P}<0.05)$. The peripheral blood $\mathrm{CD}_{4}^{+} \mathrm{CD}_{25}{ }^{+} \mathrm{Foxp}_{3}{ }^{+}$Treg of $\mathrm{CD}_{4}^{+} \mathrm{T}$ cells was significantly lower in the model group than in the control group $(\mathrm{P}<0.01$, Table 1$)$. The relationship between rat heart and lung function indices and IL-4, IL-17, Treg, and Mankin scores is shown in Table 2.

\begin{tabular}{|c|c|c|c|c|c|c|c|c|}
\hline \multirow[t]{2}{*}{ Index } & \multicolumn{2}{|c|}{ IL-4 } & \multicolumn{2}{|c|}{ IL-17 } & \multicolumn{2}{|c|}{ Treg } & \multicolumn{2}{|c|}{ Mankin } \\
\hline & $\mathrm{r}$ & $\mathrm{P}$ & $\mathrm{r}$ & $\mathrm{P}$ & $\mathrm{r}$ & $\mathrm{P}$ & $\mathrm{r}$ & $\mathrm{P}$ \\
\hline E & 0.65 & 0.08 & -0.84 & 0.002 & 0.98 & 0.08 & -0.79 & 0.03 \\
\hline A & -0.53 & 0.19 & 0.45 & 0.47 & 0.32 & 0.45 & 0.62 & 0.26 \\
\hline $\mathrm{E} / \mathrm{A}$ & 0.79 & 0.03 & -0.79 & 0.03 & 0.64 & 0.47 & -0.83 & 0.004 \\
\hline $\mathrm{FEF}_{50}$ & -0.23 & 0.73 & -0.23 & 0.73 & 0.42 & 0.37 & 0.62 & 0.07 \\
\hline $\mathrm{FEF}_{75}^{50}$ & -0.07 & 0.95 & 0.41 & 0.32 & 0.40 & 0.41 & -0.57 & 0.04 \\
\hline $\mathrm{FEV}^{75}$ & -0.03 & 0.83 & -0.18 & 0.61 & 0.39 & 0.28 & -0.67 & 0.07 \\
\hline $\mathrm{PEF}^{1}$ & -0.01 & 0.75 & -0.27 & 0.43 & 0.48 & 0.21 & -0.63 & 0.21 \\
\hline
\end{tabular}

$\mathrm{OA}=$ osteoarthritis; $\mathrm{IL}=$ interleukin; $\mathrm{E}$ = early left ventricular diastolic peak velocity; $\mathrm{A}$ = late left ventricular diastolic peak velocity; $\mathrm{FEF}_{50}=$ maximal expiratory flow at a volume of $50 \%$ of vital capacity; $\mathrm{FEF}_{75}=$ maximal expiratory flow at a volume of $75 \%$ of vital capacity; $\mathrm{FEV}_{1}=$ forced expiratory volume in $1 \mathrm{~s} ; \mathrm{PEF}=$ peak expiratory flow. 


\section{DISCUSSION}

Rheumatic diseases affect muscle, bone, and joints. Because of invasion of vascular and connective tissue, most rheumatic autoimmune diseases also affect the heart and lungs, which are rich in blood vessels, muscle, and connective tissue (Feng et al., 2012; Sun et al., 2012). Rheumatic-related heart and lung dysfunction confer a serious prognosis and have a negative impact on patients' quality of life. The onset of rheumatic disease may be subtle and slow, the disease course is long, and a genetic tendency is often seen. Diagnosis and treatment of rheumatic diseases present certain difficulties and may require testing for various antibodies in the blood. Because of the high incidence and mortality rate of rheumatic diseases, they have become a hot topic for medical research (Chen et al., 2008). Rheumatic diseases treated with nonsteroidal anti-inflammatory drugs (NSAIDS), glucocorticoids, and immunosuppressive agents have shown good short-term and long-term remission rates.

OA is a type of rheumatic disease that often seriously affects the quality of life of patients. It is second only to heart disease as the main reason that middle-aged men cannot work (Liu et al., 2012; Schulz et al., 2012). A recent study showed that mechanical and biological factors interact to cause an imbalance in the synthesis and degradation of cartilage cells in the joints (Zhao et al., 2010).

In the present study, after 50 days, Mankin scores of the rats in the model group were significantly lower than those in the control group. Parameters of heart function, specifically $\mathrm{E}$ and $\mathrm{E} / \mathrm{A}$, were significantly lower in the model group than in the control group; the A value increased, and relaxation of the left ventricle decreased. Pulmonary function parameters of PEF, FEF50, and FEF75 were lower in the model group than in the control group, indicating that ventilatory function of the rats in the model group was decreased which is consistent with findings reported in a previous study (Qu et al., 2010). FEV1 also decreased in the model group, suggesting the presence of small airway disease. In the model group, serum cytokine IL-4 level decreased and IL-17 level increased. Studies have shown that IL-4 can hinder the formation of osteoclasts, thus inhibiting bone resorption. The increase in IL-17 level that occurs with OA inflammation promotes the synthesis and release of nitric oxide, causing cartilage destruction. In our study, expression of $\mathrm{CD}_{4}^{+} \mathrm{CD}_{25}{ }^{+} \mathrm{Foxp}_{3}{ }^{+}$ Treg in the model group decreased. Treg can block T-cell activation, contributing to the maintenance of peripheral immune system stability (Javeed et al., 2009). CD4+ CD25+ Treg inhibits the function of immune cells. With reduction of $\mathrm{CD}_{4}^{+} \mathrm{CD}_{25}{ }^{+} \mathrm{Foxp}_{3}{ }^{+}$Treg expression, the inhibition of T-cell function decreases and the immune system becomes abnormal. This leads to a decrease in the IL-4 level and increase in the IL-17 level, thereby promoting the production of various enzymes, inflammatory cytokines, and oxygen free radicals, which in turn, leads to increased inflammation and immune system disorders that cause joint disease and compromise heart and pulmonary function (Darmochwal-Kolarz et al., 2012; Bhattacharya et al., 2013).

In summary, $\mathrm{OA}$ in the model rats in our study was associated with a decline in cardiac and pulmonary function. Correlation of this with changes in the levels of IL-4, IL-17, and Treg suggests that the underlying mechanism may be a reduction of the regulatory effect of Treg. This would cause an immune imbalance that could lead to a systemic inflammatory reaction, resulting in joint, heart, and lung injury. However, the specific mechanism still requires further study. 


\section{Conflicts of interest}

The authors declare no conflict of interest.

\section{ACKNOWLEDGMENTS}

Research supported by the Health Science and Technology Development Project of Jinan, Shandong Province.

\section{REFERENCES}

Bhattacharya K, Chandra S and Mandal C (2013). Critical stoichiometric ratio of CD4(+) CD25(+) FoxP3(+) Treg and CD4(+) CD25(-) Tresp persuades immunosuppression in patients with B-cell acute lymphoblastic leukemia. Immunology 142: 124-139.

Chen L, Shen Z, Wang G, Fan P, et al. (2008). Dynamic frequency of CD4+CD25+Foxp3+ Treg cells in psoriasis vulgaris. J. Dermatol. Sci. 51: 200-203.

Darmochwal-Kolarz D, Saito S, Tabarkiewicz J, Kolarz B, et al. (2012). Apoptosis signaling is altered in CD4 $4^{+}$D2 25 ${ }^{+} \mathrm{FoxP}^{+} \mathrm{T}$ regulatory lymphocytes in pre-eclampsia. Int. J. Mol. Sci. 13: 6548-6560.

Feng E, Gao H, Su W and Yu C (2012). Immunotherapy of rat glioma without accumulation of $\mathrm{CD}^{+} \mathrm{CD} 25^{+} \mathrm{FOXP} 3^{+}$ regulatory T cells. Neural Regen. Res. 7: 1498-1506.

Javeed A, Zhang B, Qu Y, Zhang A, et al. (2009). The significantly enhanced frequency of functional $\mathrm{CD} 4^{+} \mathrm{CD} 25^{+} \mathrm{Foxp} 3^{+}$ T regulatory cells in therapeutic dose aspirin-treated mice. Transpl. Immunol. 20: 253-260.

Liu DY, Zhao HM, Huang XY, Zuo ZQ, et al. (2012). Regulation effect of scorpio and scolopendra on CD4 + CD25 + FoxP3 + Treg cell in peripheral blood from rats with collagen-induced arthritis (CIA). Zhong Yao Cai 35: 525-528.

Qu Y, Zhang B, Liu S, Zhang A, et al. (2010). 2-Gy whole-body irradiation significantly alters the balance of CD4+ CD25T effector cells and CD4+ CD25+ Foxp3+ T regulatory cells in mice. Cell. Mol. Immunol. 7: 419-427.

Schulz VJ, Smit JJ, Bol-Schoenmakers M, van Duursen MB, et al. (2012). Activation of the aryl hydrocarbon receptor reduces the number of precursor and effector $\mathrm{T}$ cells, but preserves thymic $\mathrm{CD} 4+\mathrm{CD} 25+\mathrm{Foxp} 3+$ regulatory $\mathrm{T}$ cells. Toxicol. Lett. 215: 100-109.

Sun L, Wu J and Yi S (2012). Foxp3 is critical for human natural CD4+CD25+ regulatory T cells to suppress alloimmune response. Transpl. Immunol. 26: 71-80.

Wang GY, Zhang Q, Yang Y, Chen WJ, et al. (2012). Rapamycin combined with allogenic immature dendritic cells selectively expands $\mathrm{CD}^{+}{ }^{+} \mathrm{CD} 25^{+} \mathrm{Foxp}^{+}$regulatory T cells in rats. Hepatobiliary Pancreat. Dis. Int. 11: 203-208.

Zhang J, Deng L, Xiong X, Wang P, et al. (2011). Effect of tiotropium bromide on expression of CD(8) (+)CD (25) (+) FoxP $(3)(+)$ regulatory T cells in patients with stable chronic obstructive pulmonary disease. J. Huazhong Univ. Sci. Technol. Med. Sci. 31: 463-468.

Zhao ZX, Feng XB, Shi T, Yang C, et al. (2010). The comparison of CD4(+) CD25(+) Treg, IL-10 and TGF-beta from lymph and blood in bronchial asthmatic rat and the effect of dexamethasone on it. Xi Bao Yu Fen Zi Mian YI Xue Za Zhi 26: 238-241. 